\section{Granulozyten, stabkernige}

H. Baum

Institut für Laboratoriumsmedizin, Mikrobiologie und Blutdepot, Regionale Kliniken Holding RKH GmbH, Ludwigsburg, Deutschland

\section{Synonym(e) Stabkernige}

Englischer Begriff band granulocyte

Definition Intermediäre Reifungsstufe der myeloischen Zellreihe mit stabförmigem Zellkern.

Beschreibung Der stabkernige Granulozyt (s. Abbildung) ist eine morphologisch differenzierbare intermediäre Reifungsstufe der Granulozytopoese.

In der Abbildung ist ein stabkerniger Granulozyt zu sehen, daneben sind in dieser Zelle eine toxische Granulierung und ein Döhlekörperchen darstellbar $(1000 \times$, May-GrünwaldGiemsa-Färbung):

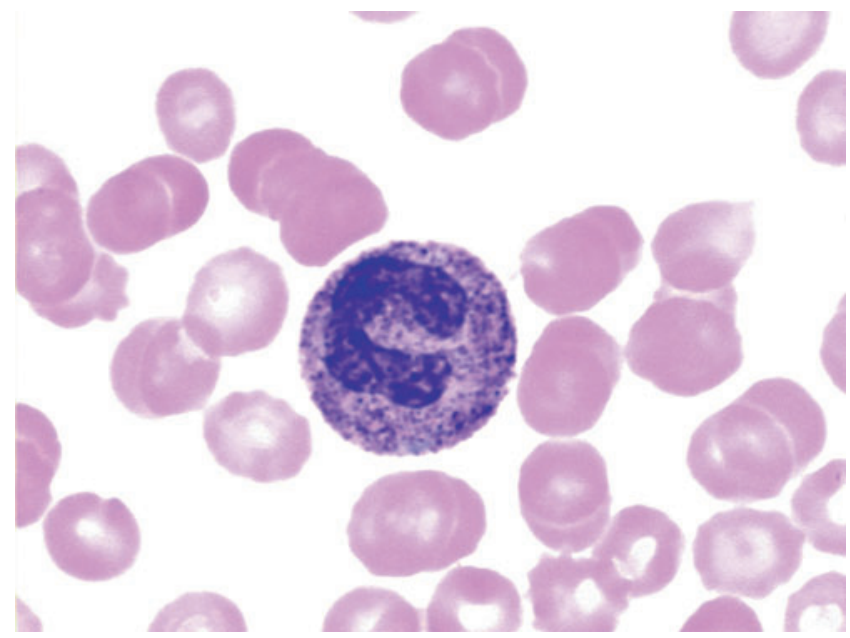

Der stabkernige Granulozyt unterscheidet sich vom segmentkernigen neutrophilen Granulozyten nur durch das Fehlen einer Segmentierung des Kernes. Der Kern ist stabförmig bis hufeisenförmig gebogen. Dabei ist die schmalste Stelle des Kernes nicht schmaler als 1/3 der maximalen Kernbreite. Das Kernchromatin ist dicht und streifig, das Zytoplasma oxyphil mit kleinen sekundären, spezifischen Granula. Der stabkernige Granulozyt gehört zu den reifen Formen der Myelopoese und besitzt nicht mehr die Fähigkeit zur Zellteilung. Beim Gesunden sind bis zu $5 \%$ der Zellen im peripheren Blut stabförmige Granulozyten. Etwa 15 \% aller Knochenmarkzellen gehören zu den stabkernigen Granulozyten, innerhalb der myeloischen Reihe sind es $24 \%$.

\section{Literatur}

Boll I (1991) Knochenmark-Zytologie. In: Boll I, Heller S (Hrsg) Praktische Blutzelldiagnostik. Springer, Berlin/Heidelberg/New York, S $287-291$ 